\title{
Management of Incontinence After Orthotopic Bladder Substitution Post-Radical Cystectomy
}

\author{
Marc P. Schneider $^{1}$ - Fiona C. Burkhard ${ }^{1}$ \\ Published online: 3 July 2019 \\ (C) The Author(s) 2019
}

\begin{abstract}
Purpose of Review Incontinence after orthotopic bladder substitution (OBS) post-radical cystectomy can be devastating for the patient and its treatment a challenge for the physician. The aim of this narrative review was to summarize the available evidence on treatment options for incontinence after OBS and to facilitate deciding on treatment strategies.

Recent Findings Despite good continence rates after OBS, incontinence remains an issue and treatment poses a challenge for which limited evidence exists.

Summary Treatment of incontinence therapy after orthotopic bladder substitution (OBS) post-radical cystectomy currently remains a challenge with limited evidence to aid treatment decisions. After a sound patient assessment and exclusion of anatomical or underlying problems, conservative management including pelvic floor muscle training is generally considered the first line of therapy. Drugs can be used as second-line therapy in specific cases, before refraining to third-line surgical options.
\end{abstract}

Keywords Orthotopic bladder substitution · Neo-bladder · Cystectomy · Incontinence

\section{Introduction}

Radical cystectomy, bilateral pelvic lymph node dissection with urinary diversion, remains the standard of care for muscle invasive bladder cancer and has been for decades. Orthotopic bladder substitution (OBS) is the type of urinary diversion most closely mimicking normal lower urinary tract function and maintaining an intact body image [1]. The goal of an OBS, whichever of the many published techniques used, is to create a low pressure, high capacity reservoir.

Functional outcome (continence and sexual function) after OBS is one of the main issues affecting long-term quality of life (QoL). Published continence rates in large series range from 90 to $92 \%$ for daytime continence and $80 \%$ for night time continence [2,3]. Once continence is achieved, it is likely to remain stable up to at least 20 years post-surgery [4].

This article is part of the Topical Collection on Post-Prostatectomy and Acquired Voiding Dysfunction

Fiona C. Burkhard

fiona.burkhard@insel.ch

1 Department of Urology, Inselspital, University Hospital Bern, University of Bern, CH-3010 Bern, Switzerland
The best strategy is to avoid development of incontinence. Careful patient selection, a meticulous surgical technique, and good patient education postoperatively are of utmost importance to ensure good outcomes. Continence after OBS is determined by specific characteristics of the reservoir (such as a cross-folded intestinal segment with transection of circular fibers, type of bowel, spheroidal shape, and functional capacity of approximately $500 \mathrm{ml}$ ) and retained function of the outlet mechanism. For example, double folding of $40 \mathrm{~cm}$ of ileum will, according to the law of LaPlace, increase the initial volume of the ileal segment from $125 \mathrm{ml}$ to $500 \mathrm{ml}$, while at the same time reducing the pressure by a factor of 4 [5]. By slowly prolonging the intervals between emptying, the capacity of the reservoir can gradually be increased to about $500 \mathrm{ml}$. Other factors contributing to continence are meticulous surgical techniques including attempted nerve sparing, atraumatic sphincter preparation, preservation of maximum functional urethral length, and no kinking of the outlet leading to residual and consequently infected urine as well as age.

Kessler et al. assessed 381 consecutive men undergoing cystectomy and orthotopic bladder substitution and found in multivariate analysis that attempted nerve sparing significantly affected daytime continence whereas age significantly affected nighttime continence [6]. The pathophysiological mechanisms behind these findings may be that with age, urethral closing pressure and urethral innervation decrease. The resulting lack 
of sensation may affect both voluntary and involuntary sphincter contractions and impact continence. Nighttime incontinence may be explained by absent neurofeedback to the brain. Patients do not wake up to empty their bladder and thus overflow incontinence can occur. Increased nighttime diuresis and shift of free water into the concentrated urine may further attribute to incontinence. In a more recent study evaluating no vs unilateral vs bilateral nerve sparing, any degree of nerve sparing was associated with both day- and nighttime continence, which became even more apparent over time [7].

In women, a uterus- and vagina-sparing technique not only maintains reproductive function but also allows for a less extended dissection around the vagina and better preservation of the autonomic nerves thereby improving continence rates [8]. In a recent systematic review including 15 publications on this topic, Veskimae et al. found a large variability in reported continence rates ranging from 59 to $71 \%$ day- and $42-71 \%$ nighttime continence [9••]. Age $>65$ and preoperative urethral pressure profiles are factors reported to affect continence after OBS post-radical cystectomy and thus careful preoperative patient selection may improve outcome $[8,10]$. Other than stress urinary incontinence (SUI), urinary tract infections (UTI), urinary retention with overflow incontinence and in women vesicovaginal fistula can be causes of urinary leakage.

Despite good continence rates in patients with OBS, incontinence remains a bothersome issue in a number of patients and treatment remains challenging. The aim of this narrative review was to summarize the existing evidence and aid treatment selection.

\section{Diagnostic Evaluation}

Time to achieve continence with an OBS is approx. 3 months for daytime and 6 months for nighttime continence. Diagnostic workup of incontinence in patients with an OBS consists of a detailed history including an evaluation of voiding habits, urinalysis, and determination of residual urine by ultrasound or catheterization. A bladder diary of at least $48 \mathrm{~h}$ assessing reservoir capacity and voiding frequency and a pad test for quantification of incontinence can give additional information.

The importance of adhering to a strict postoperative voiding schedule cannot be overstated. Poor voiding habits such as non-adherence to 4 hourly voiding intervals both during the day and at night with a voided volume of 350-500 ml can lead to a low capacity, high-pressure reservoir due to frequent emptying or overdistension and incomplete emptying due to prolonged voiding intervals.

Urinalyis and urine culture should be performed routinely at each follow up to identify UTI. In men midstream urine is adequate, in women we prefer catheter urine. Nitrite, in our experience, is often false positive, and a low number of erythrocytes and leucocytes are often observed and should be considered normal in the dipstix test. Urine culture is the only reliable way to diagnose bacteriuria or UTI.

Cystoscopy can help identify mucosal prolapse, anastomotic stricture, or obstruction from residual prostatic tissue with incomplete emptying and overflow incontinence. Urodynamic assessment may be helpful in rare cases to identify high-pressure contractions, in particular in patients with nighttime incontinence [11].

Evaluation in women should include a vaginal examination to assess for prolapse or a vaginal mass leading to retention and overflow or a vesicovaginal fistula [12].

\section{Discussion of Treatment}

After excluding or treating the cause of residual urine, leakage associated with a UTI should be treated with antibiotics. If SUI has been established and other causes of leakage ruled out, conservative treatment for uncomplicated SUI, such as pelvic floor physiotherapy, lifestyle modifications including drinking habits and weight loss as well as renewed instruction on voiding techniques, and intervals with an OBS, should be considered the first line of therapy. In general, patients are instructed to perform regular pelvic floor muscle exercises after surgery and to continue with these after achieving continence.

\section{Stress Urinary Incontinence}

\section{Drug Treatment}

Duloxetine is an antidepressant that inhibits reuptake of both serotonin and norepinephrine and is available for treating SUI in some countries. Although many physicians will try using this drug, there is currently no published evidence for OBS.

\section{Bulking Agents}

Transurethral injection of bulking agents, a minimally invasive procedure, may be a good option in patients, not qualifying for general anesthesia. There is limited evidence showing good short-term results in female OBS patients suffering from incontinence [13, 14]. However, long-term results seem to show a less positive outcome. Development of urethrovaginal fistula after bulking agents had been described [15••].

\section{Slings}

Sling procedures, pubovaginal slings or transobturator slings, are more invasive treatment alternatives although the available evidence is limited and contradictory. Quek et al. assessed the efficacy and safety of pubovaginal slings in four female OBS patients [16]. Two patients with dermal graft slings had an uneventful follow-up but were unable to void after sling placement and 
needed intermittent self-catheterization. Despite this, the outcome was considered satisfactory. Two patients, who underwent an autologous pubovaginal sling, had severe complications associated with the dissection of the retropubic space. One patient ultimately died of an entero-cutaneous fistula and subsequent sepsis. The other patient developed an entero-pouch fistula and ultimately underwent conversion to a continent cutaneous diversion. In another series with four pubovaginal slings placed subperiostally and four transobturator slings in six patients, success was limited with one patient dry and one improved [15••].

The transobturator approach has a lower risk of intestinal perforation; however, reported results are mixed and TOS are at best moderately successful [17]. These results highlight the challenges of a retropubic approach after OBS. Before sling placement, patients should be informed about the general high risk of postoperative complications. As patients with an OBS tend to void by straining, most patients with a suburethral sling will need to perform intermittent self-catheterization and should be instructed prior to surgery. If sling placement is considered, an autologous sling should be the preferred option.

In women with severe incontinence, where conservative or less invasive options are generally of limited success and taking the risk of sling surgery into account, diversion into a continent or incontinent urinary diversion may be the most prudent approach.

\section{Artificial Urethral Sphincter}

Male OBS patients suffering from moderate to severe incontinence may be considered for artificial urethral sphincter implantation. O'Connor et al. showed significant short-term improvement with good tolerance and a reliable effect in a small series of men after artificial urethral sphincter implantation [18]. SimmaChiang et al. reported data on continence and safety of artificial urethral sphincter implantation in 12 patients with a mean followup of 21.7 months [19]. They demonstrated a significant improvement in continence, a good quality of live and safety [19]. Vainrib et al. assessed efficacy and adverse events in 36 OBS patients, who underwent artificial urethral sphincter implantation [20]. They found significant improvement in continence with a low complication rate. Hence, artificial urethral sphincter is a viable option in men with incontinence after OBS.

\section{"Overactive Bladder" in OBS}

There is limited evidence that oxybutynin and verapamil might be effective to treat both day- and nighttime incontinence in OBS patients [21]. El-a et al. found that both oxybutynin and verapamil lead to improvement of both clinical symptoms and urodynamic parameters, without major side effects. Oxybutinin seemed to be more effective, however, with a higher rate of side effects.

Imipramine, a tricyclic antidepressant, has been reported to have a positive effect on nocturnal urinary incontinence. [22]

Intramural injections of onabotulinum toxin A into the neobladder wall may be another effective alternative, although both the optimal injection technique and dosage remain to be elucidated. Hoag et al. Int Neurourol J 2016.

\section{Mucosal Prolapse or Protrusion, Residual Prostate Tissue, and Urethral Stricture}

Bladder outlet obstruction from residual prostatic tissue, urethral strictures, or mucosal prolapse or protrusion can lead to incomplete emptying with urinary tract infection and/or overflow incontinence. Cystoscopy will confirm stenosis and residual prostate tissue as well as intestinal mucosa prolapsing into the outlet. To detect obstructing prolapse, the outlet must be inspected while emptying the bladder and mucosal tissue can be seen to prolapse into the outlet (Fig. 1a). Appropriate treatment is transurethral incision or resection of the obstructing tissue (Fig. 1b).
Fig. 1 Mucosal prolapse or protrusion, $\mathbf{a}$ before and $\mathbf{b}$ after resection

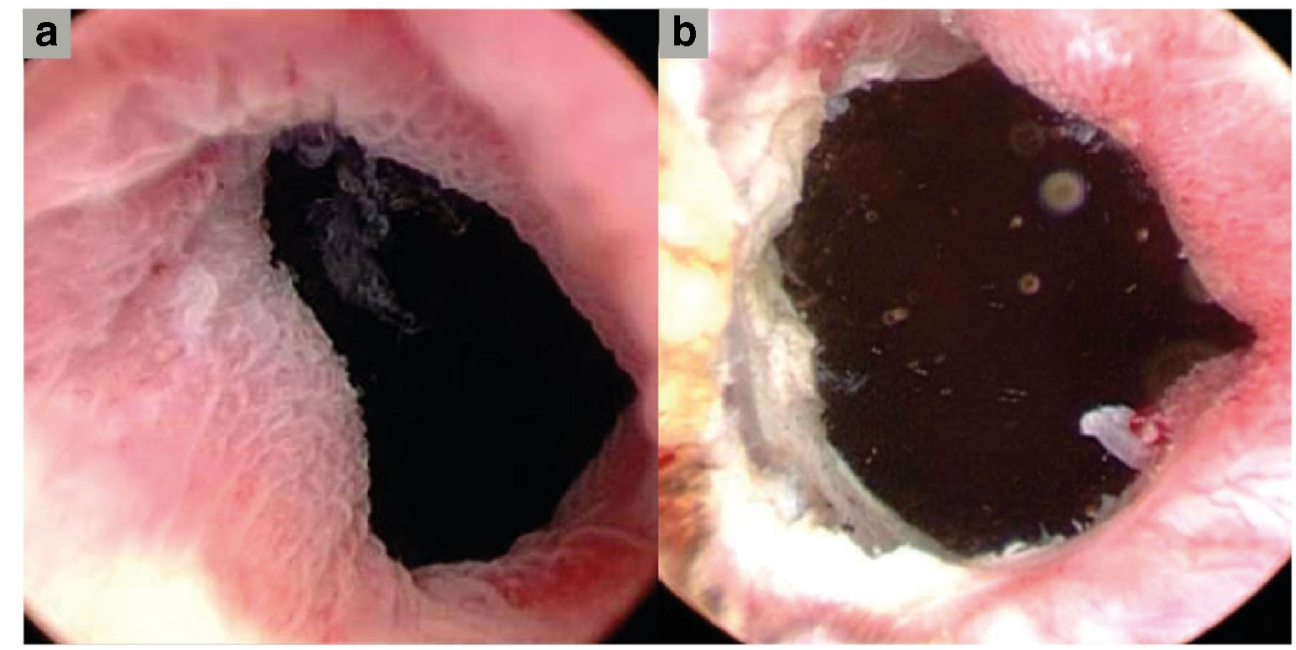


Our preferred option for men with bothersome stress urinary incontinence after OBS is an artificial urinary sphincter, and in women, diversion to a continent cutaneous reservoir. Many patients will shy away from repeat open surgery, and in these cases, we will use bulking agents (Bulkamid), with good patient satisfaction in the few cases treated. We have had less than optimal results with sling placement including the transobturator approach, as the bladder is very low behind the symphysis and bladder perforation difficult to avoid.

\section{Conclusions}

As treatment of incontinence after OBS can be challenging, the best strategy is to avoid it developing. Careful patient selection, a meticulous nerve-sparing surgical technique, and detailed postoperative patient education all contribute to improved continence. If incontinence occurs after OBS, patients should be well-informed about the limitations of the currently available options.

In women, bulking agents are a minimally invasive option; however, long-term results are less than optimal. Slings are associated with a significant risk of severe complications and the need for ISC. Conversion to a continent or incontinent reservoir may be a better option in women with severe incontinence.

In men, an artificial urinary sphincter is a viable option with good outcome and low complication rates.

In summary, incontinence after OBS remains a challenge. Treatment options are available, but treatment success remains questionable, the risk of complications is high, and the level of evidence is generally low.

\section{Compliance with Ethical Standards}

Conflict of Interest Marc P. Schneider and Fiona C. Burkhard declare that they have no conflict of interest.

Human and Animal Rights and Informed Consent This article does not contain any studies with human or animal subjects performed by any of the authors.

Open Access This article is distributed under the terms of the Creative Commons Attribution 4.0 International License (http:// creativecommons.org/licenses/by/4.0/), which permits unrestricted use, distribution, and reproduction in any medium, provided you give appropriate credit to the original author(s) and the source, provide a link to the Creative Commons license, and indicate if changes were made.

\section{References}

Papers of particular interest, published recently, have been highlighted as:

•- Of major importance

1. Alfred Witjes J, Lebret T, Comperat EM, Cowan NC, De Santis M, Bruins HM, et al. Updated 2016 EAU guidelines on muscle- invasive and metastatic bladder cancer. Eur Urol. 2017;71(3): 462-75. https://doi.org/10.1016/j.eururo.2016.06.020.

2. Studer UE, Burkhard FC, Schumacher M, Kessler TM, Thoeny H, Fleischmann A, et al. Twenty years experience with an ileal orthotopic low pressure bladder substitute-lessons to be learned. J Urol. 2006;176(1):161-6. https://doi.org/10.1016/s0022-5347(06) 00573-8.

3. Hautmann RE, Volkmer BG, Schumacher MC, Gschwend JE, Studer UE. Long-term results of standard procedures in urology: the ileal neobladder. World J Urol. 2006;24(3):305-14. https://doi. org/10.1007/s00345-006-0105-z.

4. Furrer MA, Roth B, Kiss B, Nguyen DP, Boxler S, Burkhard FC, et al. Patients with an orthotopic low pressure bladder substitute enjoy long-term good function. J Urol. 2016;196(4):1172-80. https://doi.org/10.1016/j.juro.2016.04.072.

5. Hinman F Jr. Selection of intestinal segments for bladder substitution: physical and physiological characteristics. J Urol. 1988;139(3):519-23.

6. Kessler TM, Burkhard FC, Perimenis P, Danuser H, Thalmann GN, Hochreiter WW, et al. Attempted nerve sparing surgery and age have a significant effect on urinary continence and erectile function after radical cystoprostatectomy and ileal orthotopic bladder substitution. J Urol. 2004;172(4 Pt 1):1323-7.

7. Furrer MA, Studer UE, Gross T, Burkhard FC, Thalmann GN, Nguyen DP. Nerve-sparing radical cystectomy has a beneficial impact on urinary continence after orthotopic bladder substitution, which becomes even more apparent over time. BJU Int. 2018;121(6):935-44. https://doi.org/10.1111/bju.14123.

8. Gross T, Meierhans Ruf SD, Meissner C, Ochsner K, Studer UE. Orthotopic ileal bladder substitution in women: factors influencing urinary incontinence and hypercontinence. Eur Urol. 2015;68(4): 664-71. https://doi.org/10.1016/j.eururo.2015.05.015.

9.• Veskimae E, Neuzillet Y, Rouanne M, MacLennan S, Lam TBL, Yuan Y, et al. Systematic review of the oncological and functional outcomes of pelvic organ-preserving radical cystectomy (RC) compared with standard RC in women who undergo curative surgery and orthotopic neobladder substitution for bladder cancer. BJU Int. 2017;120(1):12-24. https://doi.org/10.1111/bju.13819. Recent systematic review providing a detailled overview on oncological and functional outcomes after radical cystectomy comparing pelvic organ preserving and standard radical cystectomy.

10. Rouanne M, Legrand G, Neuzillet Y, Ghoneim T, Cour F, Letang N, et al. Long-term women-reported quality of life after radical cystectomy and orthotopic ileal neobladder reconstruction. Ann Surg Oncol. 2014;21(4):1398-404. https://doi.org/10.1245/ s10434-013-3458-8.

11. el-Bahnasawy MS, Osman Y, Gomha MA, Shaaban AA. Persistent and occasional nocturnal enuresis in orthotopic urinary diversion: is there a urodynamic difference? BJU Int. 2005;96(9):1373-7. https://doi.org/10.1111/j.1464-410X.2005.05852.x.

12. Ali-El-Dein B, Gomha M, Ghoneim MA. Critical evaluation of the problem of chronic urinary retention after orthotopic bladder substitution in women. J Urol. 2002;168(2):587-92.

13. Wilson S, Quek ML, Ginsberg DA. Transurethral injection of bulking agents for stress urinary incontinence following orthotopic neobladder reconstruction in women. J Urol. 2004;172(1):244-6. https://doi.org/10.1097/01.ju.0000132153.30662.60.

14. Tchetgen MB, Sanda MG, Montie JE, Faerber GJ. Collagen injection for the treatment of incontinence after cystectomy and orthotopic neobladder reconstruction in women. J Urol. 2000;163(1):212-4.

15.• Bailey GC, Blackburne A, Ziegelmann MJ, Lightner DJ. Outcomes of surgical management in patients with stress urinary incontinence and/or neovesicovaginal fistula after orthotopic neobladder diversion. J Urol. 2016;196(5):1478-83. https://doi.org/10.1016/j.juro. 
2016.06.009. A recent study reporting on the outcomes of surgical management of incontinence in women with an orthotopic neobladder.

16. Quek ML, Ginsberg DA, Wilson S, Skinner EC, Stein JP, Skinner DG. Pubovaginal slings for stress urinary incontinence following radical cystectomy and orthotopic neobladder reconstruction in women. J Urol. 2004;172(1):219-21. https://doi.org/10.1097/01. ju.0000132149.63834.33.

17. Badawy AA, Saleem MD, Abolyosr A, Abuzeid AM. Transobturator vaginal tape (inside-out) for stress urinary incontinence after radical cystectomy and orthotopic reconstruction in women. Arab J Urol. 2012;10(2):182-5. https://doi.org/10.1016/j. aju.2012.02.010.

18. O'Connor RC, Kuznetsov DD, Patel RV, Galocy RM, Steinberg GD, Bales GT. Artificial urinary sphincter placement in men after cystectomy with orthotopic ileal neobladder: continence, complications, and quality of life. Urology. 2002;59(4):542-5.

19. Simma-Chiang V, Ginsberg DA, Teruya KK, Boyd SD. Outcomes of artificial urinary sphincter placement in men after radical cystectomy and orthotopic urinary diversions for the treatment of stress urinary incontinence: the University of Southern California experience. Urology. 2012;79(6):1397-401. https://doi.org/10. 1016/j.urology.2012.02.006.
20. Vainrib M, Simma-Chiang V, Boyd SD, Ginsberg DA. Potential risk factors and outcomes of artificial urinary sphincter placement after radical cystectomy and orthotopic neobladder urinary diversion. Neurourol Urodyn. 2013;32(7):1010-3. https://doi.org/10. 1002/nau.22345.

21. El-Bahnasawy MS, Shaaban H, Gomha MA, Nabeeh A. Clinical and urodynamic efficacy of oxybutynin and verapamil in the treatment of nocturnal enuresis after formation of orthotopic ileal neobladders. A prospective, randomized, crossover study. Scand J Urol Nephrol. 2008;42(4):344-51. https://doi.org/10.1080/ 00365590701832726.

22. Zhang YG, Song QX, Song B, Zhang DL, Zhang W, Wang JY. Diagnosis and treatment of urinary incontinence after prthotopic ileal neobladder in China. Chin Med J. 2017;130(2):231-5. https://doi.org/10.4103/0366-6999.198012.

Publisher's Note Springer Nature remains neutral with regard to jurisdictional claims in published maps and institutional affiliations. 